\title{
DINÂMICA TERRITORIAL DO SETOR SUCROENERGÉTICO EM SANTA VITÓRIA, MINAS GERAIS
}

\section{TERRITORIAL DYNAMICS OF THE SUGAR- ENERGY SECTOR IN SANTA VITÓRIA, MINAS GERAIS}

\author{
Patrícia Francisca de Matos \\ Professora da Unidade Acadêmica de Geografia e do Programa de Pós-Graduação em Geografia da \\ Universidade Federal de Catalão, Catalão, GO, Brasil. \\ patriciafmatos@yahoo.com.br \\ Glaúcio José Marafon \\ Professor do Instituto de Geografia e do Programa de Pós-Graduação em Geografia da Universidade \\ Estadual do Rio de Janeiro, Rio de Janeiro, RJ, Brasil. \\ glauciomarafon@hotmail.com
}

\section{Resumo}

No início do século XXI, ocorreu uma expansão acelerada no território brasileiro de produção de cana-de-açúcar, devido o projeto dos biocombustíveis, que colocou essa cultura como a principal opção na produção de álcool, criando novas paisagens, novas formas de produção e modificando os usos do território, especialmente, o estado de Goiás e Minas Gerais. O estado de Minas Gerais consolidou-se como um dos maiores produtores de cana-de-açúcar do país, em virtude da implantação de diversas usinas no seu território, com destacada importância para o Triângulo Mineiro/Alto Paranaíba. Cerca de 9,5\% das 746.828.157 toneladas no Brasil, em 2018, foi produzido em Minas Gerais, e destes, 69\%, produzidas no Triângulo Mineiro/Alto Paranaíba. A territorialização do setor sucroenergético, num curto espaço de tempo, metamorfoseou a estrutura produtiva, de forma que a cultura da cana-de-açúcar ocupou e ocupa o espaço. Todos esses municípios seguiram a tendência de crescimento desta monocultura em detrimento da diminuição de outras lavouras, promovendo novas territorialidades e novas configurações na paisagem, mediadas por uma lógica de produção globalizada de açúcar, etanol e energia.

Palavras Chaves: Setor sucroenergético. Território. Minas Gerais.

\begin{abstract}
At the beginning of the 21st century, there was an accelerated expansion in the Brazilian territory of sugarcane production, due to the biofuels project, which placed this culture as the main option in the production of alcohol, creating new landscapes, new forms of production and modifying the uses of the territory, especially the states of Goiás and Minas Gerais. The state of Minas Gerais has consolidated himself as one of the largest sugarcane producers in the country, because of the establishment of many plants in his
\end{abstract}


territory, with particular importance for the Triângulo Mineiro / Alto Paranaíba. About 9,5\% of the 746.828.157 tons in Brazil, in 2016, was produced in Minas Gerais, and of these, $6,93 \%$, produced in the Triângulo Mineiro / Alto Paranaíba. The territorialization of the sugar-energy sector, in a short time, metamorphosed the productive structure, so the sugarcane culture occupied and still occupies the space. All these municipalities followed the growth trend of this monoculture to the detriment of the decrease of other crops, promoting new territorialities and new landscape configurations, mediated by a logic of globalized production of sugarcane, ethanol and energy.

Keywords: Sugar-energy sector. Territory. Minas Gerais.

\section{Introdução}

O Brasil tem tido um crescimento significativo nas duas últimas décadas das monoculturas de cana-de-açúcar. Esta atividade vem constituindo um novo cenário da produção agrícola, sobretudo, de Goiás e Minas Gerais, em um viés sustentado pelo discurso do desenvolvimento econômico e da produção de energia "limpa".

O estado de Minas Gerais, no contexto da política de incentivos por parte do governo para expansão da produção dos biocombustíveis, teve um aumento no volume produzido, a partir de 2000. Cerca de 9,5\% das 746.828.157 toneladas no Brasil, em 2018, foi produzido em Minas Gerais, e destes, 69\%, produzidas no Triângulo Mineiro/Alto Paranaíba.

A mesorregião do Triângulo Mineiro e Alto Paranaíba (mapa 1) é composta por 66 municípios distribuídos em sete microrregiões; Ituiutaba, Frutal, Uberlândia, Uberaba, Patrocínio, Araxá e Patos de Minas, é a segunda maior do estado em área territorial com $90.545 \mathrm{~km}^{2}$. (IBGE, 2018). A configuração espacial da produção de cana-de-açúcar está concentrada sobretudo, nos municípios da microrregião de Frutal, Uberaba, Ituiutaba e Uberlândia, com 227.190; 223.300; 81.844 e 53.996 hectares respectivamente, totalizando cerca de 90\% da área plantada no Triângulo Mineiro/ Alto Paranaíba em 2018.

Castilho (2015) ressalta que é possível identificar duas regiões do setor sucroenergético com potencial para atingir elevados níveis de competitividade no Cerrado: o Sul Goiano e o Sudoeste do Mato Grosso do Sul. Soma-se as essas duas regiões mencionadas pelo autor a mesorregião do Triângulo Mineira/Alto Paranaíba, cujos municípios que mais produzem são Uberaba, Frutal, Santa Vitória, Conceição das Alagoas, Campo Florido, Iturama, Ituiutaba, Limeira do Oeste, Conquista e Água Comprida. 
Mapa 1: Localização do Triângulo Mineiro e Alto Paranaíba/MG

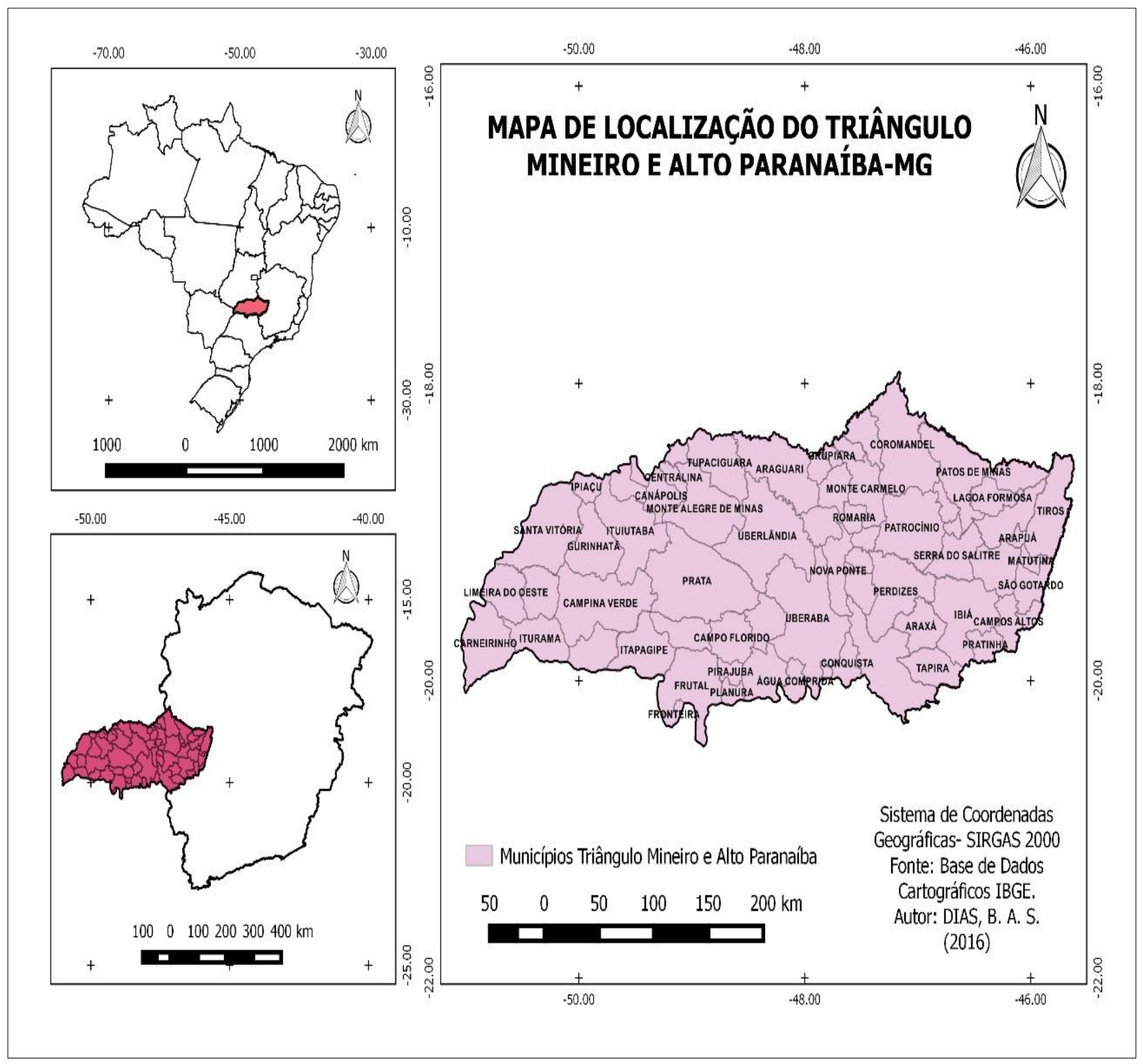

Diante dessas considerações, o objetivo desse texto é apresentar a dinâmica da produção da cana-de-açúcar no Triângulo Mineiro/Alto Paranaíba, especialmente em dez municípios que representam pela área plantada e quantidade produzida a força de grupos nacionais e internacionais do setor sucroenergético, e por fim, uma análise do município de Santa Vitória, que em uma década passou por uma mudança no uso do território pelo setor sucronergético.

Para a pesquisa, foram utilizados reflexão teórica; levantamento de dados do Instituto Brasileiro de Geografia e Estatística (IBGE); União da Indústria da cana-de-açúcar (ÚNICA); Associação das Indústrias Sucronergéticas de Minas Gerais (SIAMIG, Ministério da Agricultura, Pecuária e Abastecimento (MAPA), União dos Produtores de Bioenergia 
(UDOP), da SIAMIG, dos Portais NovaCana e INFOCANA e realização de trabalho de campo nos municípios de maior produção.

\section{A expansão do setor sucronergético no Brasil}

O início do século XXI é marcado por um “novo" processo de expansão do cultivo de cana no território brasileiro, devido os incentivos governamentais para produção de etanol por meio da cana-de-açúcar - principal fonte de energia da matriz energética dos biocombustíveis no Brasil. Os subsídios do governo para o setor centralizaram-se em recursos do BNDES (Banco Nacional de Desenvolvimento Econômico e Social), isenções fiscais para a instalação de usinas e investimentos em logística.

Assim, a lógica espacial para a implantação de usinas está diretamente relacionada às vantagens fiscais do governo, aos aspectos físicos e ao acesso à matéria-prima, fatores que possibilitam a produção e expansão, especialmente para os estados de Goiás, Minas Gerais, Mato Grosso e Paraná.

Outro fator muito importante a se considerar é o Decreto Presidencial 6.961/2009, que aprovou o Zoneamento Agroecológico da Cana, objetivando fornecer subsídios técnicos para a formulação de políticas públicas com vistas à expansão e à produção sustentável de cana-de-açúcar no país. Todo o território nacional foi objeto de estudo, com exceção das áreas que abrangem os Biomas Amazônia e Pantanal e a bacia do Alto Paraguai (MAPA, 2018).

Conforme orientações do Zoneamento Agroecológico da Cana, os estados com maior capacidade para a expansão da cana-de-açúcar são Goiás, Mato Grosso do Sul, São Paulo, Minas Gerais e Paraná, além da parcela do Mato Grosso que não compõe a Amazônia Legal. A maioria das áreas se encontra no bioma Cerrado e a Mesorregião do Triângulo Mineiro está incluída como apta ao cultivo da cana-de-açúcar.

Analisando a produção nacional por meio da participação de cada estado de 2000 a 2018, as mudanças mais evidentes correspondem a expansão da cana no próprio estado de São Paulo que já ranqueava a produção desde a década de 1970, seguido por Minas Gerais, Goiás, Mato Grosso do Sul e Paraná, e nestes, o norte-noroeste e oeste-sudoeste do estado paulista, o Triângulo Mineiro, o sul goiano e o centro-sul do Mato Grosso do Sul. 
Os estados de São Paulo, Goiás, Minas Gerais, Paraná e Mato Grosso do Sul produziram 89,36 \% da produção nacional, enquanto que os estados da Paraíba, Pernambuco, Alagoas e Mato Grosso contribuíram com 7,33\% da produção nacional, totalizando esses nove estados em 2018 com 96.69 \% da produção nacional de cana-deaçúcar. Pelos dados da tabela 1, observa-se a participação da produção a nível nacional, com destaque para os estados da região Centro-Sul que teve crescimento muito considerável no período analisado. E os estados do Nordeste, sofreram decréscimo, principalmente a partir de 2008, conforme dados do IBGE.

Tabela 1: Brasil - porcentagem (\%) de produção de cana nos principais estados produtores nos anos de 2000 a 2018 (anos selecionados)

\begin{tabular}{lllllll}
\hline Estados & $\mathbf{2 0 0 0}$ & $\mathbf{2 0 0 4}$ & $\mathbf{2 0 0 8}$ & $\mathbf{2 0 1 2}$ & $\mathbf{2 0 1 6}$ & $\mathbf{2 0 1 8}$ \\
\hline Paraíba & $1.22 \%$ & $1.53 \%$ & $0.97 \%$ & $0.81 \%$ & $1.19 \%$ & $0.76 \%$ \\
Pernambuco & $4.65 \%$ & $4.57 \%$ & $3.15 \%$ & $1.97 \%$ & $2.54 \%$ & $1.68 \%$ \\
Alagoas & $8.52 \%$ & $6.33 \%$ & $4.52 \%$ & $3.83 \%$ & $3.04 \%$ & $2.16 \%$ \\
Minas Gerais & $5.73 \%$ & $5.85 \%$ & $7.42 \%$ & $9.77 \%$ & $8.9 \%$ & $9.48 \%$ \\
São Paulo & $57.96 \%$ & $57.68 \%$ & $59.82 \%$ & $56.32 \%$ & $54.58 \%$ & $57.98 \%$ \\
Paraná & $7.1 \%$ & $7.86 \%$ & $7.94 \%$ & $6.64 \%$ & $6.41 \%$ & $5.37 \%$ \\
Mato Grosso do Sul & $1,78 \%$ & $2.3 \%$ & $3.31 \%$ & $5.23 \%$ & $6.42 \%$ & $6.66 \%$ \\
Matos Grosso & $2.59 \%$ & $3.44 \%$ & $2.45 \%$ & $2.37 \%$ & $2.73 \%$ & $2.73 \%$ \\
Goiás & $3.1 \%$ & $3.37 \%$ & $5.13 \%$ & $8.09 \%$ & $9.09 \%$ & $9.87 \%$ \\
Demais estados & $10.45 \%$ & $7.07 \%$ & $5.29 \%$ & $4.97 \%$ & $5.1 \%$ & $3.31 \%$ \\
\hline Total & $\mathbf{1 0 0 \%}$ & $\mathbf{1 0 0 \%}$ & $\mathbf{1 0 0 \%}$ & $\mathbf{1 0 0 \%}$ & $\mathbf{1 0 0 \%}$ & $\mathbf{1 0 0 \%}$ \\
\hline
\end{tabular}

Fonte: Produção Agrícola Municipal (PAM) - IBGE, 2018.

Org: MATOS, P, F, 2019.

O crescimento da produção de cana-de-açúcar no Brasil impulsionado pelo setor sucronegertico para produção de etanol, açúcar e da energia. Conforme a ÚNICA (2018), 96\% das usinas que operam no país são mistas, ou seja, produzem etanol e açúcar. A região Nordeste possui, um número maior de usinas produtoras apenas de açúcar, com exceção dos estados da Bahia e Maranhão. Usinas que produzem apenas etanol se concentram em São Paulo e Goiás.

Após mais de quatro séculos, a produção de cana-de-açúcar, que teve como principal finalidade a produção de açúcar, passou também a servir como matéria-prima para a produção de álcool, ganhando destaque como uma alternativa de combustível a nível mundial no final da década de 1970, e posteriormente a duas décadas, para produção 
de etanol. Além da produção de etanol e açúcar, as usinas têm realizado a geração de energia elétrica por meio do bagaço da cana, constituindo, mais um produto da cana para reprodução do capital. Conforme dados do IBGE (2018) cerca de 400 usinas de açúcar e etanol existentes no país geram eletricidade para abastecer suas próprias atividades e, destas, 100 geram excedentes comercializáveis.

O Brasil é o maior exportador mundial de açúcar, respondendo por $45 \%$ do total comercializado no mundo, produziu em 2000, 16.198 toneladas, e em 2016, 33.928 toneladas. A Índia, China e Tunísia são os principais destinos do açúcar produzido no Brasil. O açúcar é uma commodity internacional, com o preço determinado pela Bolsa de Valores de Nova York levando em conta a produção e a oferta mundial. Além do abastecimento interno, a produção de etanol ainda é destinada para exportação, tendo como principais destinos, Estados Unidos, China e Índia. (IBGE, 2018).

Minas Gerais consolidou-se como um dos maiores produtores de cana-de-açúcar do país, em virtude da implantação de diversas usinas nos seus territórios, com destacada importância para o Triângulo Mineiro/Alto Paranaíba, consolidando uma região estratégica para investimentos de grupos nacionais e estrangeiros do setor sucroenergético. Os aspectos físicos, somados à infraestrutura da logística e aos incentivos governamentais, têm contribuído para esse cenário, consolidando uma região estratégica para investimentos de grupos nacionais e estrangeiros do setor sucroenergético.

\section{A dinâmica territorial do setor sucroenergético em Minas Gerais}

Santos e Silveira (2001) afirmam que as grandes empresas usam o território de modo seletivo, pois escolhem e hierarquizam os espaços mais viáveis para uma produção competitiva. O Triângulo Mineiro/Alto Paranaíba, notadamente a partir de 2000, passou por nova dinâmica de produção da cana-de-açúcar, sendo considerada como uma das regiões competitivas do setor sucroenergético. Para Castilho e Frederico (2010), a região competitiva é a expressão geográfica da produção na era da globalização.

Pereira (2012) assegura que o Triângulo Mineiro se apresenta como um espaço privilegiado para a expansão dos cultivos, recebendo, na primeira década do século atual, um novo conjunto de agentes e infraestruturas que aumentou a produção na região. Desde a década de 1970, este espaço passou por uma reestruturação produtiva com a inserção 
Dinâmica territorial do setor sucroenergético

Patrícia Francisca de Matos em Santa Vitória, Minas Gerais Glaúcio José Marafon

das monoculturas de grãos, constituindo a principal área da agropecuária de Minas Gerais no que concerne à produção de commodities agrícolas, como soja, milho, café e carnes.

Conforme dados do IBGE, a área plantada de cana-de-açúcar no estado de Minas Gerais passou de 292.751 hectares, no ano de 2000, para 921.870 hectares, em 2018, dos quais 651.497 hectares situam-se no Triângulo Mineiro/ Alto Paranaíba, o que corresponde a 70,67\% da área plantada do estado no referido ano. Esta porcentagem, em 2000, era de 43\%. Portanto, de 2000 para 2018, houve um aumento de 524.997 mil hectares de área plantada.

Como resultado da ampliação da área plantada, a produção da cana-de-açúcar no Triângulo Mineiro foi de 10.076.488 toneladas e atingiu 51.814.167 toneladas em 2018, o que representa $73 \%$ do total produzido no estado, ou seja, trata-se de uma produção territorialmente muito concentrada. Em uma análise comparativa da produção de todas as regiões do estado de Minas Gerais, verifica-se o incremento da produção do Triângulo Mineiro em relação à das demais mesorregiões do estado e, também, à produção do território nacional. O Gráfico 1 mostra a expansão da produção confirmando que a região foi "capturada" pelo capital do setor sucroenergético.

Gráfico 1: Minas Gerais - quantidade produzida (t) de cana nas cinco mesorregiões com maior produção nos anos de 2000 a 2018 (anos selecionados).

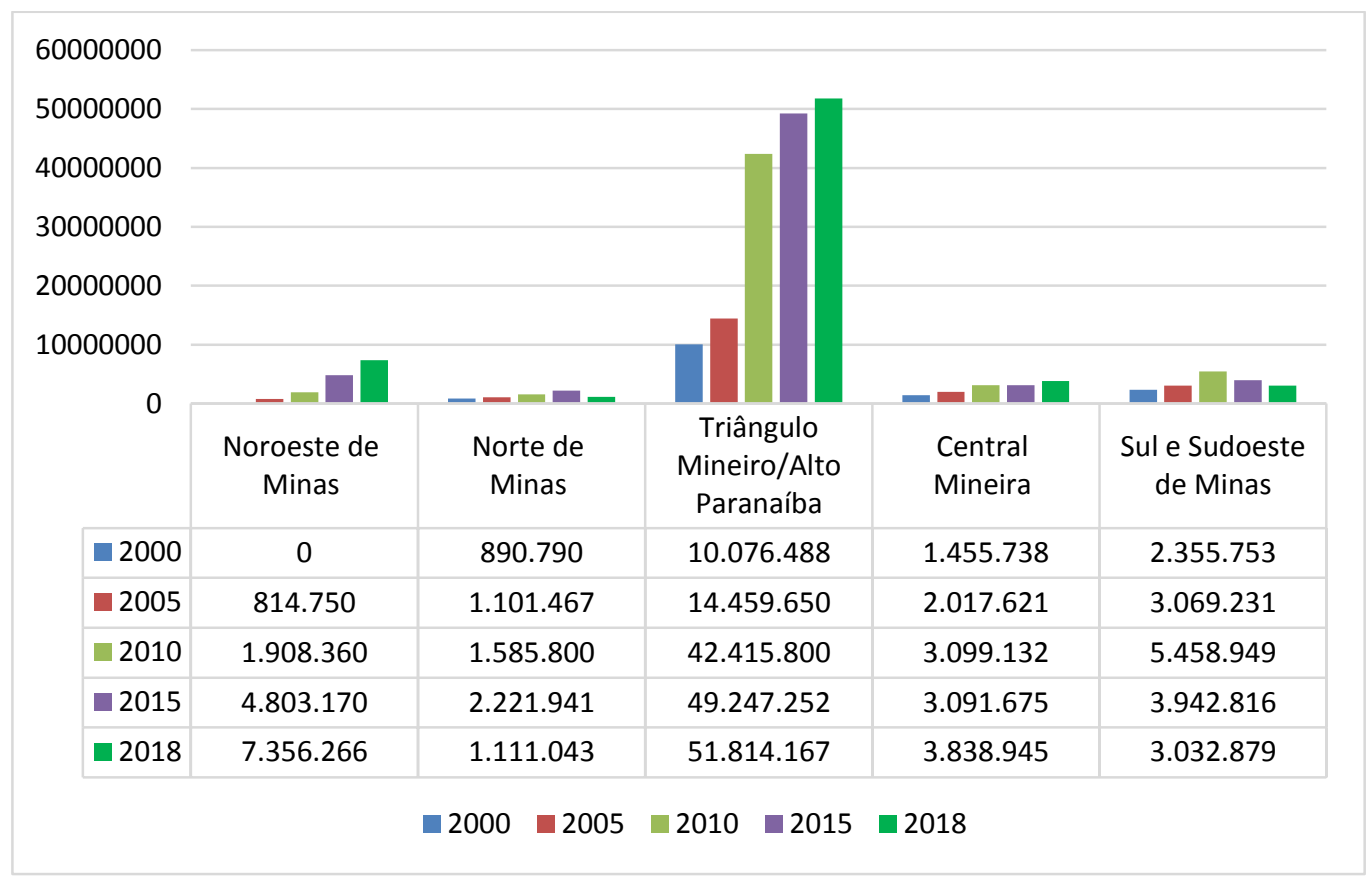

Fonte: Produção Agrícola Municipal (PAM) - IBGE, 2018.

Org: MATOS, P, F, 2019. 
Respeitante à dimensão das áreas ocupadas pelo plantio de cana-de-açúcar, denota-se que esta cresceu 524.997 hectares de 2000 a 2018, constituindo maior aumento de todas as monoculturas. A área cultiva com permaneceu com expansão constante, mas não na proporção da cana-de-açúcar, como mostram os dados da Tabela 2. A soja, um cultivo do agronegócio, somado com a cana-de-açúcar dominam a área plantada.

Tabela 2: Triângulo Mineiro/Alto Paranaíba - área plantada (hectares) de cana-deaçúcar, café, milho e soja, 2000-2018 (anos selecionados)

\begin{tabular}{ccccc}
\hline Ano & Cana-de-açúcar & Café & Milho & Soja \\
\hline $\mathbf{2 0 0 0}$ & 126.500 & 149.568 & 337.086 & 445.651 \\
$\mathbf{2 0 0 5}$ & 176.791 & 146.556 & 371.741 & 755.353 \\
$\mathbf{2 0 1 0}$ & 492.440 & 155.929 & 333.245 & 595.705 \\
$\mathbf{2 0 1 5}$ & 632.163 & 157.916 & 411.412 & 715.796 \\
$\mathbf{2 0 1 8}$ & 651.497 & 165.065 & 416.884 & 813.304 \\
\hline \multicolumn{5}{c}{ Org: MATOS, P, F, 2018. } \\
\end{tabular}

Ao passo que ocorre a expansão dos canaviais, acontece a inversão com a produção de arroz e feijão. A partir dos dados do IIBGE, observa-se que, em 2000, a região do Triângulo Mineiro cultivava 25.596 hectares de arroz e 23.199 de feijão. Ao longo dos anos, a área plantada de arroz diminuiu, decaindo para apenas 106 hectares em 2018. Neste mesmo ano, a de feijão passou para 33.873 hectares. Juntas, as duas culturas representaram cerca de 5\% da área ocupada pela cana-de-açúcar em 2018. Dessa forma, a mudança na produção é evidenciada nos dados, bem como na paisagem dos municípios que possuem usinas ou que estão próximos destas.

A territorialização de uma usina significa muito mais que mudanças na produção agrícola, gera desterritorialização de sujeitos, conflitos fundiários, supressão de vegetação, poluição dos recursos hídricos, entre outros efeitos, causadores de impactos ambientais e sociais.

O estado de Minas Gerais possui 34 usinas, e destas, 21 encontram-se na Mesorregião do Triângulo Mineiro/Alto Paranaíba, controladas por grupos nacionais e estrangeiros que atuam na atividade e/ou em outros setores econômicos. Os grupos de capital internacional totalizam cinco: a Bunge com três unidades: Frutal, Itapagipe e Santa Juliana; a Bristish Petroleum com uma em Ituiutaba e a Dow Química com uma em Santa 
Vitória. Os grupos de capital nacional estão representados em 15 unidades (ÚNICA, 2018).

Na Mesorregião do Triângulo Mineiro/Alto Paranaíba, alguns municípios concentram a produção de cana-de-açúcar, principalmente os que têm usinas instaladas ou estão próximos delas, porquanto a territorialização do setor promove mudanças para além da escala local.

O município de Uberaba é o maior produtor de cana da mesorregião; a área plantada passou de 5 mil hectares, em 2000, para 84.000 mil hectares, em 2018. O município de Frutal constitui o segundo maior produtor do estado; a área plantada de cana-de-açúcar cresceu de 3,6 mil hectares para 54.200 mil hectares. Conceição das Alagoas, com 45 mil hectares o terceiro maior produtor em 2018. Em Santa Vitória, quarto produtor, a área plantada de cana-de-açúcar era de 40 hectares em 2000 passou para 40.000 mil hectares em 2018, o que consiste em um abrupto crescimento (Tabela 3).

Tabela 3: Triângulo Mineiro/Alto Paranaíba - área plantada (hectares) de cana-deaçúcar nos dez municípios de maior produção nos anos de 2000 a 2018 (anos

\begin{tabular}{|c|c|c|c|}
\hline Municípios & 2000 & 2010 & 2018 \\
\hline Uberaba & 5.000 & 46.000 & 84.000 \\
\hline Frutal & 3.600 & 30.689 & 54.200 \\
\hline Santa Vitória & 40 & 25.867 & 40.000 \\
\hline Conceição das Alagoas & 15.000 & 40.000 & 45.000 \\
\hline Iturama & 19.608 & 30.900 & 39.000 \\
\hline Campo Florido & 800 & 17.500 & 36.300 \\
\hline Ituiutaba & 500 & 24.000 & 26.000 \\
\hline Água Comprida & 4.000 & 19.500 & 18.100 \\
\hline Limeira do Oeste & 2.502 & 18.000 & 40.000 \\
\hline Conquista & 11.000 & 15.000 & 18.200 \\
\hline Total & 62.050 & 284.956 & 400.800 \\
\hline
\end{tabular}

Fonte: Produção Agrícola Municipal (PAM) - IBGE (2018).

Org: MATOS, P, F, 2019.

Todos os dez municípios com maior produção canavieira do estado de Minas Gerais possuem usinas em seus territórios. Em alguns desses municípios, a área ocupada pela cana-de-açúcar ultrapassa os $90 \%$ da área cultivada por lavouras temporárias e 
permanentes por exemplo: Iturama, com 97,41\%; Santa Vitória, com 92,97\% e Limeira do Oeste, com 97,18\%. Este cenário evidencia que o setor desencadeou a especialização agrícola de cana-de-açúcar nesses municípios e a monopolização do território. Além dos municípios citados, destaca-se os com mais de 50\%; Frutal e Campo Florido, conforme tabela 4 .

Tabela 4: Triângulo Mineiro/Alto Paranaíba - área plantada (hectares) de lavouras temporárias e permanentes cana-de-açúcar nos dez maiores municípios produtores em 2018

\begin{tabular}{lccc}
\hline Municípios & $\begin{array}{c}\text { Lavouras } \\
\text { temporárias e } \\
\text { Permanentes } \\
\text { (ha) }\end{array}$ & $\begin{array}{c}\text { Lavouras } \\
\text { de cana (ha) }\end{array}$ & $\begin{array}{c}\text { Porcentagem \% } \\
\text { da área (ha) de cana } \\
\text { em relação as lavouras } \\
\text { temporárias e } \\
\text { permanentes }\end{array}$ \\
\hline Uberaba & 219.609 & 84.000 & $38,24 \%$ \\
Frutal & 98.662 & 54.200 & $54,93 \%$ \\
Santa Vitória & 43.024 & 40.000 & $\mathbf{9 2 , 9 7 \%}$ \\
Conceição das Alagoas & 114.340 & 45.000 & $39,35 \%$ \\
Iturama & 40.036 & 39.000 & $\mathbf{9 7 , 4 1 \%}$ \\
Campo Florido & 68.567 & 36.300 & $52,94 \%$ \\
Ituiutaba & 63.646 & 26.000 & $40,85 \%$ \\
Água Comprida & 39.487 & 18.100 & $45,83 \%$ \\
Limeira do Oeste & 41.154 & 40.000 & $\mathbf{9 7 , 1 9 \%}$ \\
Conquista & 37.511 & 18.200 & $48,51 \%$ \\
\hline
\end{tabular}

Fonte: Produção Agrícola Municipal (PAM) - IBGE (2018).

Org: MATOS, P, F, 2019.

Mediante os dados apresentados, constata-se uma especialização agrícola de canade-açúcar, que torna os territórios abrangidos vulneráveis aos investimentos e ao controle do setor sucroenergético. Todavia, esta não é uma realidade específica dos municípios retromencionados, outros mais foram capturados pela força do capital deste setor e, também, apresentam aumento abrupto da atividade canavieira e modificação na dinâmica da produção agrícola e pecuária, assim como as formas de uso do território. 


\section{O setor sucroenergético em Santa Vitória}

O setor sucroenergético no Triângulo Mineiro têm conseguido ocupar territórios e expandir sua produção, tornando uma das principais culturas da região. Com isso, novos significados econômicos, configurando um tempo impregnado pelas territorialidades do setor, modificando o campo e a cidade e constituindo a principal atividade econômica ou uma das principais.

Para Castilho (2015), entre as consequências mais imediatas da cana-de-açúcar está um maior "engessamento" do uso do território, ou seja, uma vez que a indústria tenha sido implantada, necessariamente, haverá o cultivo da monocultura nas proximidades. Infere-se que, ao territorializar, a usina pode transformar a dinâmica produtiva dos municípios derredores, não possuindo um limite municipal como já mencionado.

Dos municípios capturados pelo setor sucroenergético de cana-de-açúcar no Triângulo Mineiro, Santa Vitoria, é um deles. A produção de cana-de-açúcar nesse município era irrelevante até 2007. A partir de então, com a instalação da Usina Santa Vitória Açúcar e Álcool (SVAA), elevou a produção neste território, atingindo 55.500 hectares plantados em 2016, constituindo no referido ano o terceiro lugar em área plantada de cana-de-açúcar no estado de Minas Gerais. Junto com outros municípios vizinhos foram responsáveis por cerca de $8,80 \%$ da área plantada com cana-de-açúcar do Triângulo Mineiro ou, ainda, por 8,88\% da produção do estado (Tabela 5).

Tabela 5: Microrregião de Ituiutaba (MG) - área plantada (hectares) de cana (anos selecionados)

\begin{tabular}{lcccccc}
\hline \multicolumn{1}{c}{ Municípios } & $\mathbf{2 0 0 0}$ & $\mathbf{2 0 0 4}$ & $\mathbf{2 0 0 8}$ & $\mathbf{2 0 1 2}$ & $\mathbf{2 0 1 6}$ & $\mathbf{2 0 1 8}$ \\
\hline Cachoeira Dourada & - & - & 3.600 & 8.150 & 2.485 & - \\
Capinópolis & 20 & 5.500 & 8.372 & 9.150 & 2.485 & 2.684 \\
Gurinhatã & 20 & 25 & 35 & 3.640 & 8.600 & 8.600 \\
Ipiaçu & 15 & 1.561 & 6.032 & 4.260 & 4.600 & 4.600 \\
Ituiutaba & 500 & 60.00 & 18.700 & 20.100 & 26.000 & 26.000 \\
Santa Vitória & 40 & 5 & 6.200 & 28.400 & 55.500 & 40.000 \\
\end{tabular}


À medida que o cultivo de cana-de-açúcar se expande, acontece a inversão com a produção de arroz, feijão, milho e outros cultivos alimentares. Segundo dados do IBGE (2016), em 2000, o município de Santa Vitória produzia 265 hectares de arroz. Ao longo dos anos, o arroz diminuiu, declinando, em 2018, para apenas 10 hectares de produção, isto é, quase extinta a produção. Em 2000 até 2004 o milho representava a lavoura mais relevante para o município, com 2.500 hectares, mas, a sua área plantada decaiu, chegando em apenas 180 hectares em 2018.

A soja sofreu muitas oscilações no período analisado. De todo modo, a cana-deaçúcar lidera a área ocupada no município, dominando os espaços de outras lavouras que equivale a 92,97\% da área plantada de lavouras temporárias do município (Tabela 6). Esses dados são muito preocupantes porque, mostra que a atividade domina a produção agrícola do município, tomou espaço de cultivares alimentares e da pecuária extensiva. $\mathrm{O}$ mapa de uso da terra (mapa 2) mostra a abrangência das áreas ocupadas pela agricultura, e como a cana prevalece as áreas de cultivo, consequentemente domina no uso do solo no ano de maior produção que foi em 2016.

Tabela 6: Santa Vitória (MG) - área plantada (ha) de lavouras temporárias, cana, soja e milho (anos selecionados)

\begin{tabular}{|c|c|c|c|c|}
\hline Ano & $\begin{array}{c}\text { Total da área } \\
\text { de lavouras } \\
\text { temporárias (ha) }\end{array}$ & $\begin{array}{l}\text { Área com } \\
\text { cana (ha) }\end{array}$ & $\begin{array}{l}\text { Área com } \\
\text { soja (ha) }\end{array}$ & $\begin{array}{c}\text { Área } \\
\text { com milho (ha) }\end{array}$ \\
\hline 2000 & 3.880 & 40 & 180 & 2.500 \\
\hline 2004 & 13.729 & 5 & 5.400 & 5.500 \\
\hline 2008 & 7.206 & 6.200 & -- & 800 \\
\hline 2012 & 30.380 & 28.400 & 87 & 1.380 \\
\hline 2016 & 56.901 & 54.000 & 1.115 & 1.255 \\
\hline 2018 & 42.926 & 40.000 & 1.920 & 180 \\
\hline
\end{tabular}


Dinâmica territorial do setor sucroenergético

Patrícia Francisca de Matos em Santa Vitória, Minas Gerais

Glaúcio José Marafon

Mapa 1: Uso do solo no município de Santa Vitória, Minas Gerais, 2016.

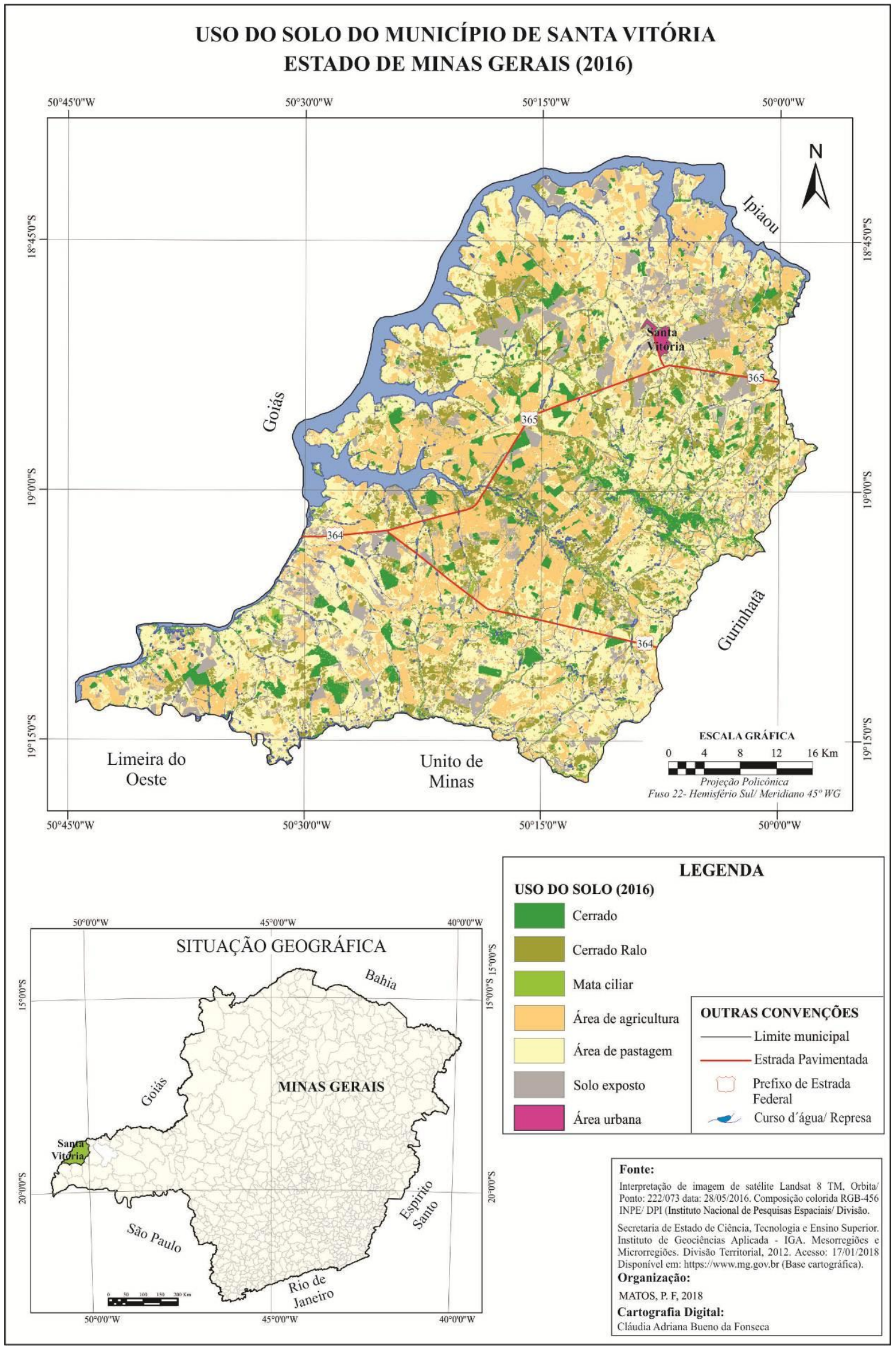


Uma análise dos dados da pecuária, mostra que a quantidade de bovinos sofreu declínio, justamente, em 2008 - quando foram instaladas as usinas no município - e nos demais períodos analisados manteve-se instável. As usinas necessitavam de áreas para plantio e, diante disso, muitos proprietários rurais desistiram da pecuária para tornaremse parceiros agrícolas das usinas. Referente à produção de leite, Santa Vitória manteve a média nos analisados. Por possuir grandes agroindústrias de leite na região, como a Nestlé e Canto de Minas a disputa por territórios acontece.

Gráfico 2: Santa Vitória (MG) - quantidade de bovinos e produção de leite (anos selecionados)

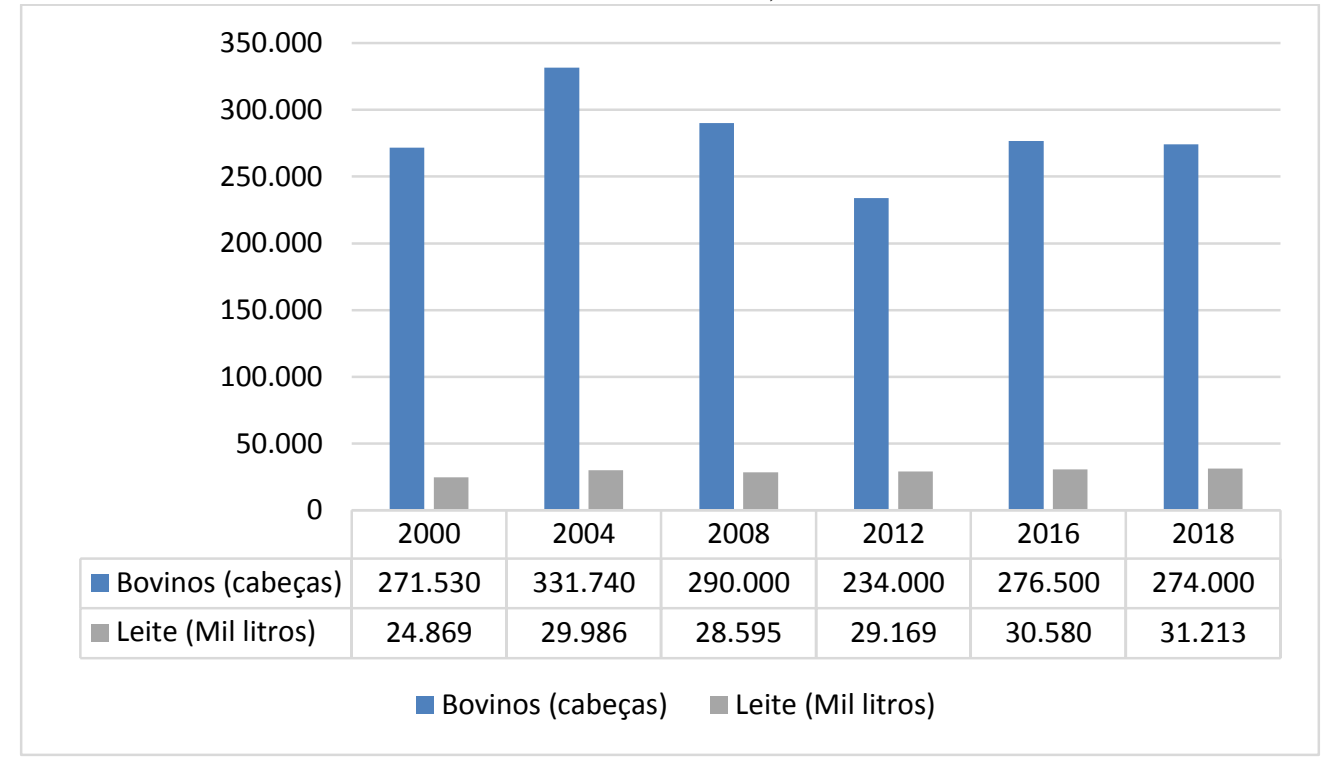

Fonte: Produção Agrícola Municipal (PAM) - IBGE, 2018.

Org: MATOS, P, F, 2019.

Com normatizações das áreas destinadas à produção de cana, as usinas expandem os canaviais, especialmente em propriedades mais próximas às usinas por meio de contratos de arrendamentos e parcerias. Para Castilho (2015, p. 4) "mais importante do que a distância física é a distância medida em custo e, sobretudo neste caso, em tempo. Por isso, a logística de abastecimento local das usinas é um elemento central da organização produtiva”. Além da distância outros fatores são relevantes como; relevo plano, abundância hídrica, fertilidade do solo, e documentação da propriedade regularizada.

Como exemplo, a relação de quinze parceiros de uma usina no município de Santa Vitória (quadro1), cuja variação do tamanho das propriedades, sendo a menor 30 hectares e a maior 1.762 hectares. Concernente, distância das propriedades com a usina, fator 
primordial para renda da terra, altera de 3 a 41 quilômetros nos casos mencionados no quadro abaixo. A mesma usina, tem parceiros com distância que chega a 100 quilômetros.

\begin{tabular}{ccc} 
Quadro 1: Propriedades parceiras/arrendadas de uma usina em Santa Vitória (MG) \\
\hline $\begin{array}{c}\text { Área total da } \\
\text { propriedade em hectares }\end{array}$ & $\begin{array}{c}\text { Área de cultivo com } \\
\text { cana em hectares }\end{array}$ & $\begin{array}{c}\text { Distância da usina } \\
\text { parceira }\end{array}$ \\
\hline 1.762 & 1.652 & 3 \\
724 & 651 & 28 \\
225 & 212 & 12 \\
398 & 367 & 22 \\
245 & 231 & 19 \\
520 & 483 & 39 \\
135 & 126 & 30 \\
213 & 194 & 24 \\
374 & 349 & 22 \\
30 & 26 & 41 \\
30 & 27 & 40 \\
32 & 29 & 40 \\
434 & 416 & 33 \\
684 & 614 & 41 \\
246 & 232 & 20 \\
& &
\end{tabular}

Fonte: ANDRADE, V. C. S., 2017.

Org: MATOS, P. F., 2019.

Em face dos dados da produção das imagens de satélite, observa-se que num curto espaço de tempo, metamorfoseou a estrutura produtiva, de forma que o cultivo da canade-açúcar tem dominado o território. A territorialização do setor sucroenergético constituiu um dos fatores para modificar a produção agrícola de Santa Vitória, trazendo novas territorialidades e novas configurações na paisagem, mediadas por uma lógica de produção globalizada de açúcar, etanol e energia.

\section{Considerações finais}

O setor sucroenergético, em sua lógica de expansão, tem se apropriado não apenas de novas áreas, mas, de territórios, gerando conflitualidades. $\mathrm{O}$ aumento desta cultura tem ocorrido, especialmente, por meio de três formas de contrato agrícola entre as usinas e os proprietários rurais: o contrato de arrendamento, a parceria agrícola e o fornecimento de matéria-prima. Este quadro atesta uma situação de vulnerabilidade do território, a subordinação dos proprietários de terra, principalmente, dos agricultores familiares, e a restruturação produtiva dos municípios, com aumento exorbitante da produção canavieira em detrimento da produção de arroz, feijão, milho, entre outras 
culturas, o que contribui para a diminuição da produção de alimentos, a nível local e regional, e, consequentemente, afeta a soberania alimentar.

Apesar da gana das usinas para apropriarem-se de todas as "terras" de seu interesse para produção canavieira, é possível encontrar as resistências, em função dos laços culturais com a propriedade e pelo sentido que a terra tem, que decorre além do valor econômico. Ademais, há aqueles que resistem porque suas propriedades ou parte delas não atendem aos interesses das usinas. Estes proprietários se encontram "ilhados" por canaviais e vivem os impactos que a monocultura causa no meio ambiente, como os desmatamentos, o uso de agrotóxicos e a poluição do ar.

No contexto das mudanças verificadas em toda região e, notadamente, nos municípios que tiveram usinas instaladas, torna-se essencial compreender as dinâmicas que permeiam as transformações, tanto no meio rural quanto no urbano. Entre inúmeras possibilidades de investigação sobre o tema, procurou-se analisar, na presente pesquisa, a dinâmica territorial produtiva.

Indubitavelmente esse novo cenário produtivo voltado ao setor sucroenergético atende, efetivamente, a uma proposta do capital. As preocupações com uma matriz energética sustentável são discursos infidos do governo e de todos que apoiam esse modelo. No que diz respeito, ao Triângulo Mineiro/Alto Paranaíba e especificamente, o município de Santa Vitória, ainda que se afirme a contribuição da produção de cana-deaçúcar para o crescimento econômico, trata-se de mais uma atividade agrícola responsável por inúmeros efeitos sociais, culturais e ambientais, em diversas escalas.

\section{REFERÊNCIAS}

ALMEIDA, P. J.de; BUAINAN, A.M. Os contratos de arrendamento e parceria no Brasil. Revista Direito GV. São Paulo, v. 9, nº 1 p. 319-244, jan-jun, 2013.

ANDRADE, V. C. S. O novo código florestal e os impactos ambientais no entorno do reservatório de São Simão em consequência da expansão canavieira. 168f. Dissertação (Mestrado em Geografia) - Faculdade de Ciências Integradas do Pontal, da Universidade Federal de Uberlândia, 2017.

BENRARDES, J. A.; SILVA, C. A.; ARRUZZO, R. C. (Org.). Espaço e energia: mudanças no paradigma sucroenergético. Rio de Janeiro. Editora Lamparina, 2013. 
Dinâmica territorial do setor sucroenergético

Patrícia Francisca de Matos em Santa Vitória, Minas Gerais Glaúcio José Marafon

CAMPOS, N. L. Redes do agronegócio canavieiro: a territorialização do Grupo Tércio Wanderley no Triângulo Mineiro/Alto Paranaíba - MG. 2014. Dissertação (Mestrado em Geografia) - Instituto de Geografia, Universidade Federal de Uberlândia, 2014.

CASTILLO; R.; FREDERICO, S. Dinâmica regional e globalização: espaços competitivos agrícolas no território brasileiro. Mercator, Fortaleza. v. 9, n.18, p.1726, 2010.

CASTILHO, R. Região competitiva e circuito espacial produtivo: a expansão do setor sucroalcooleiro no Brasil. VII ENCONTRO NACIONAL DA ANPEGE, Curitiba, 2009. Anais... Curitiba, 2009.

Dinâmicas recentes do setor sucroenergético no Brasil: competitividade regional e expansão para o bioma Cerrado. GEOgraphia (UFF), v. 17, p. 95-119, 2015.

CASTILHO, et, al. Regiões do agronegócio, novas relações campo -cidade e reestruturação urbana. Revista da Associação Nacional de Pós-graduação e Pesquisa em Geografia (ANPEGE). v 12, n 18, 2016, p. 259-282.

FAGUNDES, F. N. Setor sucroalcooleiro: relações contratuais e determinantes do território. 189f. Dissertação (Mestrado em Geografia), Instituto de Geociências e Ciências Exatas, Universidade Estadual Paulista, Rio Claro, 2016.

IBGE. A Geografia da cana-de-açúcar https://biblioteca.ibge.gov.br/visualizacao/livros/liv101436.pdf

IBGE. Produção Municipal de Minas Gerais 1990/2016. Disponível em: <http://www.ibge.gov.br, 2018>. Acesso em: 15 abr. 2019.

IBGE. Produção agrícola nas regiões 1990/2016. Disponível em: <http://www.ibge.gov.br, 2018>. Acesso em: 16 abr. 2019.

POSTAL, A. C. M. Acesso à cana-de-açúcar na expansão sucroenergética brasileira do pós 2000: o caso de Goiás. 2014. 142f Dissertação (Mestrado em Desenvolvimento Econômico) - Instituto de Economia, Universidade Estadual de Campinas, 2014.

PEREIRA, M. F. V. As 'cidades da cana' no Triângulo Mineiro (Brasil): Para uma discussão das implicações territoriais do agronegócio e de seus nexos urbanos. In: XV Encuentro de Geógrafos de América Latina - EGAL, 2015, La Habana. Anais do XV 2015. v. 1.

Estado e mercado na definição de uma região agrícola moderna: processos e consequências no Triângulo Mineiro. In: E. da S. RAMOS FILHO; M. F. V. PEREIRA; J. de L. SANTOS; G. D. G. CLEPS; V. da C. ANDRADE. (Org.). Estado, políticas públicas e território. 1ed.São Paulo: Outras Expressões, 2017, v. 1, p. 67-86.

Os agentes do agronegócio e o uso do território no Triângulo Mineiro/Alto Paranaíba: da moderna agricultura de grãos à expansão recente da cana- de-açúcar. Revista do Departamento de Geografia - USP, vol. 23, p. 83-104, 2012. 
SANTOS, M. A natureza do espaço: técnica e tempo, razão e emoção. 4.ed. São Paulo: HUCITEC, 2006.

SANTOS, M.; SILVEIRA, M. L. O Brasil: território e sociedade no início do século XXI. Rio de Janeiro: Record, 2001.

SANTOS, H. F. Competitividade regional do setor sucroenergético na mesorregião Triângulo Mineiro/Alto Paranaíba: agricultura científica globalizada e implicações socioambientais no município de Uberaba - MG. Dissertação (Mestrado em Geografia). 281f. Campinas: IG/UNICAMP, 2017.

\section{SIAMIG/SINDAÇÚCAR. Sindicato das Indústrias Sucroenergéticas de Minas}

Gerais. Disponível em: http://www.siamig.com.br/. Acesso em jan. 2018.

UNICADATA. Banco de dados da União da Indústria de Cana-de-Açúcar. 2018. Disponível em: http://www.unicadata.com.br/. Acesso em: 10 de jun. de 2018.

Recebido em 08/03/2020.

Aceito para publicação em 09/07/2020. 